\title{
COMPARISON BETWEEN LEVEL OF INTEREUKIN 10 IN THE GINGIVAL CREVICULAR FLUID AND PERI- IMPLANT SULCULAR FLUID AROUND HEALTHY DENTAL IMPLANTS (SPLIT MOUTH STUDY)
}

\author{
Shama $\mathrm{MM}^{1}$, Aboukhadr $\mathrm{M}^{2}$, Madi $\mathrm{M}^{3}$, Abdelhady $\mathrm{S}^{4}$
}

\begin{abstract}
INTRODUCTION: Several methods are used in monitoring peri-implant clinical status most of these are periodontal in origin, unfortunately these methods only determine established disease rather than assessing early inflammatory response. Recently, Peri-implant sulcular fluid analysis become a major important index in monitoring peri-implant clinical status.

OBJECTIVE: The aim of this study was to compare and evaluate levels of interleukin 10 in the peri-implant sulcular fluid and the gingival crevicular fluid.

MATERIALS AND METHODS: Sixteen patients with functionally osseointigrated dental implants were conducted in this split mouth study. Crevicular fluid was collected by absorbent paper points, Interleukin 10 levels were evaluated by using ELISA method for interleukin 10 level from two sites in each subject,study sites: around dental implant and control sites: around antagonist tooth in the same arch. Specimens were evaluated by ELISA method for interleukin level.

RESULTS: The levels of IL-10 for neobiotech dental implant showed a mean of $4.45 \pm 0.55$ in the PISF and $2.85 \pm 0.34$ GCF and for astratech dental implant IL10 showed a mean of 3.35 \pm 0.44 in PISF and 2.75 \pm 0.41 in GCF. Levels of IL10 for the implant systems showed statistically significant higher levels in the PISF than GCF $(\mathrm{P}<0.05)$.

CONCLUSION: IL-10 can be used as site specific marker in monitoring early inflammatory changes in both gingival crevicular fluid \&periimplant sulcular fluid.
\end{abstract}

KEY WORDS: Interleukin 10, Gingival fluid, Peri-implant fluid, Astratech, Neobiotic.

1. B.D.S. Faculty of Dentistry,Alexandria University

2. Professor of Periodontology Faculty of Dentistry,Alexandria University.

3. Lecturer of PeriodontologyFaculty of Dentistry,Alexandria University.

4. Professor of Biochemistry Faculty of Dentistry,Alexandria University.

\section{INTRODUCTION}

Implant based dental rehabilitation has come to offer highly predictable and esthetical results, hence it has become one more alternative to be included in the therapeutic options for treatment of totally or partially edentulous patients.(1)

The term Osseointigration refers to "direct structural and functional connection between ordered living bone and the surface of load carrying implant".(2)

However by the wide use of dental implants the incidence of the peri-implant disease has increased and the interest in determining the etiological factors has increased as well.(3)

Although pathogens are the recognised etiological factors in inflammatory peri-implant disease, the subsequent disease progression and severity may be attributed to host response to bacterial challenge, as observed in other infectious diseases.(4)

The peri-implant sulcus is, anatomically, functionally and environmentally quite similar to periodontal crevices.(5)

Comut et al(6), observed that the peri-implant tissue had a higher fiber content and hence lower cellular content than that of gingiva around tooth when studied the connective tissue orientation around teeth and implants in a canine model.

Hannig $\mathrm{M}$ et $\mathrm{al}(7)$, observed that, after abutment placement, an acquired pellicle was formed from salivary biopolymers, it becomes adsorbed on all hard and soft tissues, and forms an interface between the implant surface and the micro organisms.

The initial tissue response to the biofilm is histologically similar at both gingival and peri-implant sites. However, a persistent microbial challenge initiates more extensive inflammatory reaction in peri-implant sites as compared to peridontal tissue.(8)

In order to maintain the clinical health of peri-implant tissues several methods to assess the prognosis and survival rates of dental implants were introduced.(9)

Determination of peri-implant clinical status by array of clinical indices of periodontal origin, such as indices recording gingival inflammation, plaque accumulation,Bleeding on probing and probing depthsare the most frequently need traditional methods of assessment.(10)

Unfortunately, rather than detecting early inflammatory response, a clinical index usually can only determine the well established soft tissue inflammatory response.(11)

As a result, scientists in the field of periodontlogy and implantology are increasingly focusing on developing sitespecific tests of laboratory origin with higher specifity and sensitivity which may overcome the well known limitations of traditional measures.(12)

The gingival crevicular fluid (GCF) is a tissue fluid that seeps through the crevicular and junctional epithelium. It is an inflammatory exudates originating from serum. Its flow 
is an important determinant of status of periodontal tissues as it reflects the cellular response in the periodontium by the constituents from the gingival crevice.(13)

In 1989, Apse et al(14), demonstrated the presence of a similar fluid in the peri-implant sulcus, which was termed the peri-implant sulcular fluid (PISF).

PISF analysis receiving more importance among site specific tests based on the understanding that it has the potential to reflect the actual status of peri-implant soft and hard tissues.(15)

Schierano et al(16), revealed that both GCF and PISF could be useful markers of early inflammation in both gingival and peri-implant tissues. They showed a significant increase in the volume of GCF and PISF for a period of 21 days of plaque accumelation around teeth and implants and a significant volumetric decrease in both fluids by 69 days.

Peri-implant microbial contamination or infection elicits an immune response regulated by the key cytokines (TNF, InerLeukin. $1 \beta$, transforming growth factor- $\beta$, Interleukin 6 , Interleukin 10) that control the progression and/or suppression or the inflammatory response. Overproduction of pro inflammatory cytokines released by monocytes/macrophages and $\mathrm{T}$ cells in response to microbial challenge can lead to the breakdown of the periodontal or peri-implant tissues.(17)

Interleukin 10 , is a cytokine with potent antiinflammatory properties, it has been implicated in the regulation of both cellular and humoral immune responses.(18)

Also, IL-10 has been reported to down regulate the production of both IL-1 alpha and beta. Sasaki and associates found that IL-10 suppresses infection-stimulated bone resorption in vivo and vitro studies. In work on rats infected with prophymonous gingivalis, they found that interleukin act as suppressor for infection stimulated bone resorption.(19)

Thus, Interleukin-10 (IL-10) is an inflammatory cytokine, produced by T-helper 2 cells, macrophages and $\beta$ cells, which inhibits synthesis of pro-inflammatory cytokines such as Il-1, Il-2, Il-6, IL-8 and TNF- $\alpha$. (20)

On the other hand, IL-10 acts as $\beta$ cell stimulator, enhancing $\beta$ cell proliferation and differentiation. This fact suggests that IL-10 can play an important role in the regulation of cellular and humoral immune response.(21)

The degree to which IL-10 is detectable depends on the ability of more potent integrated immune response to try to maintain inflammatory balance.(22)

IL-10 also inhibits recruitment of osteoclast precursors and their differentiation to mature multi-nucleated osteoclasts.(23)

Thus the aim of the study was to evaluate the levels of interleukin 10 in the gingival crevicular fluid and the periimplant sulcular fluid

\section{MATERIALS AND METHODS}

\section{1- Study Design:}

This is a split mouth study, crevicular fluid was collected from the selected subjects in two sites:

i. Around the dental implant.

ii. Around the antagonist tooth in the same arch. (control site).

\section{2- Subject Selection}

This study was conducted on 16 Egyptian patient selected from Periodontology department clinic, faculty of
Dentistry, Alexandria university, age from 26 years to 52 years, 6 males and 10 females with functionally osseointigrated implants for more than 1 year in 2 different implant system. Astratech Osseo speed ${ }^{\circ}$ (8) (Astra tech dental implants, Steinzugst, Manheim, Germany)Neobiotic IS II ${ }^{\circ} \mathrm{R}(8)$ (Neobiotech USA. Inc. 3200 Wilshire Blvd South Tower \#1120, Los Angeles, USA).

\section{- Inclusion Criteria:}

1) Clinically healthy gingiva around implants and teeth.

2) Good oral hygiene.

3) Non Smokers.

4) Patient free from systemic disease.

5) Dental plaque index $\leq 1$.

6) Pappillary bleeding index $\leq 1$.

\section{- Exclusion criteria:}

1) Presence of active infection.

2) Aggressive and chronic periodontitis patients.

3) Patients received antibiotics in the last 3 months.

4) Autoimmune disease.

5) Patients received immunosuppressive medications.

6) Patients received chemotherapy or radiotherapy.

7) Uncontrolled diabetic patients.

\section{Ethical consideration}

Benefits and drawbacks were emphasized for each patient enrolled in this study, then informed consent signed by each patient as an approval to be enrolled in the study.

\section{METHODS}

\section{Procedures}

Following history taking and clinical examination all individuals were subjected to the following.

i. Radiographic evaluation of the selected implant and teeth to evaluate healthiness selected sites (Fig 1,2).

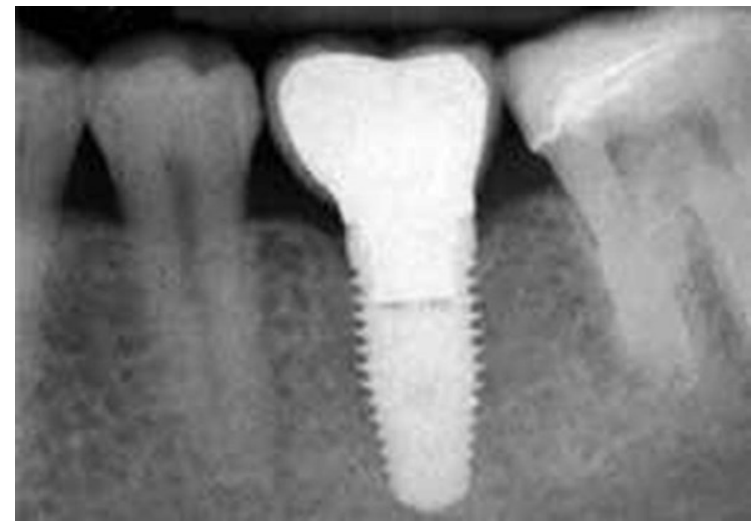

Figure 1: Periapical xray film for astratech dental implant replacing lower first molar.

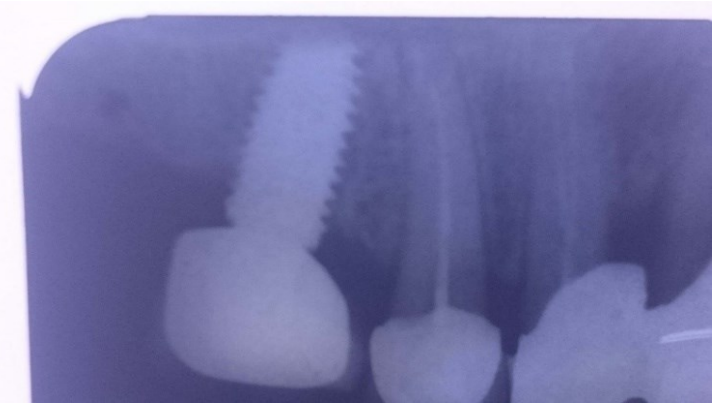

Figure 2: Periapical xray film for neobiotech dental implant replacing upper first molar. 
ii. Sample collection:

- Selected teeth and implant were carefully isolated by cotton roll placed in the mucobuccal fold then gently air dried to avoid salivary contamination of the sample.

- Paper points size 35 was used and GCF was collected by placing the paper points for 1 minute in the mesiobuccal and distobuccal sites for selected implants and teeth, carefully without pressure.

- Paper points contaminated with blood were discarded.

- Paper points were carefully placed into sterile $1.5 \mathrm{ml}$ volume low protein binding centrifuge tubes prelabeled and previously filled with 100 sterile phosphate buffered saline.

- This was immediately placed in dry ice till transportation to be stored at $-20^{\circ} \mathrm{C}$ until biochemical analysis.

Table 1: Comparison between PISF and GCF according to IL10 in Astratech

\begin{tabular}{||c|c|c||}
\hline \hline & PISF & GCF \\
\hline IL10 & & \\
Min.-Max. & $3.80-5.0$ & $2.40-3.20$ \\
Mean + SD. & $4.45 \pm 0.55$ & $2.85 \pm 0.34$ \\
Median & 4.50 & 2.90 \\
\hline T & \multicolumn{2}{|c||}{$4.086^{*}$} \\
\hline P & \multicolumn{2}{|c||}{$0.026^{*}$} \\
\hline \hline
\end{tabular}

\section{Biochemical analysis:}

Interleukin 10 obtained from PISF and GCF were measured by ELISA method. Sandwich technique using platinum ELISA eBioscience Human IL-10 (Fig 3,4). ${ }^{(24)}$

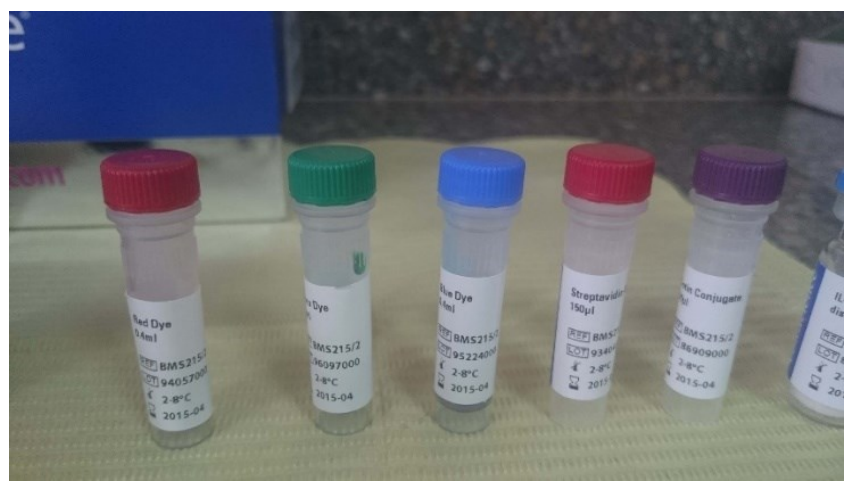

Figure 3: eBioscience IL 10 Human platinum ElISA kit.

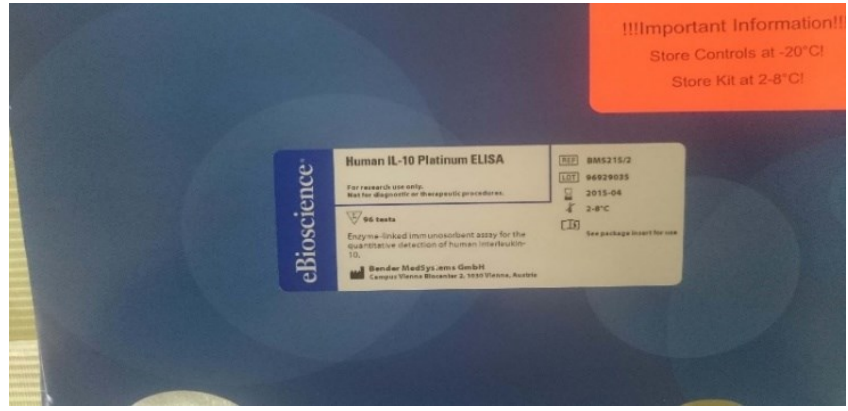

Figure 4: Dyes and conjugate for IL 10 analysis by ELISA method.

\section{STATISTICAL ANALYSIS}

Data were fed to the computer and analyzed using IBM SPSS software package version 20.0. The distributions of quantitative variables were tested for normality using Kolmogorov-Smirnov test, Shapiro Wilk test and D, Agstino test.

\section{RESULTS}

Levels of IL-10 showed significant higher levels in the periimplant sulcular fluid in astratech dental implant system than in the gingival crevicular fluid as shown in table 1 and figure 5 .

Regarding Neobiotech implant IL-10 also showed significant higher levels in the peri-implant sulcular fluid than in gingival crevicular fluid as shown in table 2 and figure 6 .

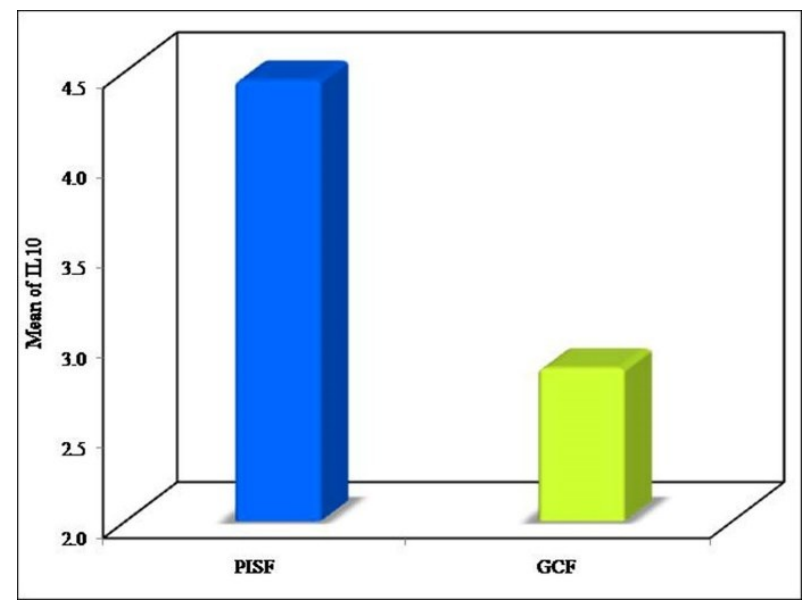

Figure 5: Comparison between IL 10 levels in the PISF and GCF in astratech dental implant.

Table 2: Comparison between PISF and GCF according to IL10 in Neobiotech.

\begin{tabular}{||r|c|c||}
\hline \hline L10 & PISF & GCF \\
\hline Min.-Max. & $2.80-3.80$ & $2.40-3.20$ \\
Mean \pm SD. & $3.35 \pm 0.44$ & $2.75 \pm 0.41$ \\
Median & 3.40 & 2.70 \\
\hline T & \multicolumn{2}{|c||}{$7.348^{*}$} \\
\hline P & \multicolumn{2}{|c||}{$005^{*}$} \\
\hline \hline
\end{tabular}

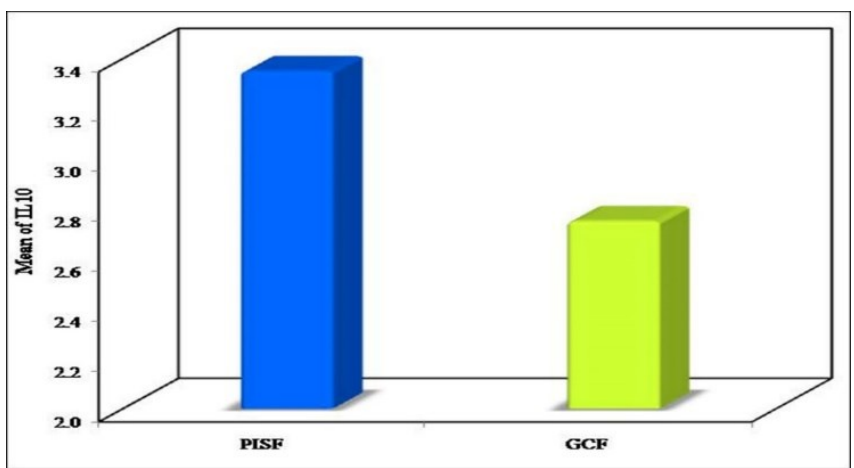

Figure 6: Comparison between IL 10 levels in the PISF and GCF in neobiotec dental implant. 


\section{DISCUSSION}

In this study assessment and comparison of interleukin 10 levels in both GCF and PISF around 2 different implant systems.

The current study was conducted on 16 healthy Egyptian subjects having functional healthy dental implants loaded from 1 to 6 years, crevicular fluid were collected around natural teeth and implants using absorbant paper points then immuno-histochemical analysis to determine levels of IL6 and IL 10 in these fluids.

Interleukin 10 results showed a significant higher levels in the peri-implants sulcular fluid than in gingival crevicular fluid.

In our study, recently loaded dental implants were excluded. This is in accordance with Pietruski et al, who observed a significant increase in interleukin levels after loading dental implants, decreased 4 months later reflecting body regeneration and repair responses. ${ }^{(26)}$

Two implant systems with moderately rough surfaces treatments were selected in this study (AstratechOsseospeed, Neobiotic ISII). The surface roughness of these implant systems were 2.4 and 2.6 respectively.

In the current study all implants used were moderately rough surface to avoid any influence of surface roughness on our results. As PaulNE et al ${ }^{(27)}$, showed that implant surface topography and roughness play a role in the expression of inflammatory cytokines.

In our study implants used possessed the same implant/Abutment connection with platform switched abutments, As BrogginiN et al ${ }^{(28)}$, showed that the implant abutment interface had an influence on the degree of inflammation in the peri-implant tissues.

In the current study, levels of interleukin 10 were measured from peri-implant and gingival crevicular fluid to assess the difference in concentration of this cytokine around dental implants and natural teeth.

Liskmann $\mathrm{S}$ et $\mathrm{al}^{(29)}$, considered important antiinflammatory and IL-10 as key cytokine in studying the correlation between the clinical parameters and cytokine levels in saliva from totally edentulous patients with periimplant disease.

On a work on rats, Sasaki $\mathrm{H}$ et $\mathrm{al}^{(30)}$, observed that interleukin 10 is the main anti inflammatory cytokine that reduces bone loss and acts as a potent suppressor of ProphymonousGingivalis induced alveolar bone resorption in Vivo.

Schierano $\mathrm{G}$ et $\mathrm{al}^{(31)}$, used IL-10 as anti inflammatory cytokine marker in studying the tissue response to dental implants.

Similar to our findings Guliz et $\mathrm{al}^{(32)}$, studied the cytokines in the peri-implant sulcular fluid around 47 dental implants (20 dental implants were healthy and 27 dental implants showing signs of inflammation). Levels of IL-10 in the periimplant sulcular fluid were higher around implants showing signs of inflammation.

Also in line with our results, Casado $\mathrm{P}$ et $\mathrm{al}^{(33)}$, studied the levels of IL-10 in the peri-implant sulcular fluid around healthy implants and implants with peri-implant disease, they showed higher levels of IL-10 around diseased implants.

In contrast to our findings, Getulio $\mathrm{N}$ et $\mathrm{al}^{(34)}$, demonstrated a non significant difference in IL-10 levels in the peri-implant sulcular fluid and the gingival crevicular fluid around healthy implants and teeth.

The current criteria for the assessment of peri-implant tissue status are based mainly on changes in the radiographic findings and clinical conditions, and it is known that only after extensive inflammation and demineralization can bone loss be detectable rediographically.

\section{CONCLUSION}

Level of IL-10 can be used as site specific marker in monitoring early inflammatory changes in both GCF \& PISF.

\section{CONFLICT OF INTEREST}

No potential conflict of interest relevant to this article was reported.

\section{REFERENCES}

1. Beatner R, Mihacl J, Schwenzer B. Biological manofunctionalization of titanium based biomaterial surfaces on Osseointigration: a flexible tool box. J R Soc. Interface 2010;7:93-105.

2. Branemark PI, ZarbGA,Albertsson T. Tissue integrated prosthesis. Osseointigration in clinical dentistry. Chicago: Quintessence publishing Co. Inc; 1985.

3. Heasmann P. Periimplant disease. Dent update. 2010;37:511-2.

4. Medzhitov R. Recognition of microorganisms and activation of immune response. Nature. 2007;449:819-26.

5. Berglundh T, Lindhe J, Erissson I, Mariello CP, Thamsen P.The soft tissue Barrier at implants and teeth.Clin Oral Implants Res. 1991;2:81-90.

6. Comute AA, Weber HP,Shortkroff S, Cui FZ, Spector M. Connective tissue orientation around dental implants in Cannine model. Clinical Oral Implant Res. 2001;12:433-40.

7. Hannig M. Transmission electron microscope study of in vivo pellicle formation on dental restorative materials. Eur J Oral Sci. 1997;105:422-33.

8. Lindhe J, Berglundh T, Ericsoon I. Experimental breakdown of peri-implant and periodontal tissues. A study on beagle dog.Clin oral Implants Res. 1992;3:9-16.

9. Albrektsson T, Zarb G, Worthington P, Eriksson AR. The longterm efficacy of currently used dental implants: a review and proposed critera for success. Int. J Oral Maxillofac Implants. 1986;1:11-25.

10. Löe H, Sillncss J, Periodontal disease in Pregnancy. 1. Pervalence and Severity.ActaOdontol Scand. 1963;21:533-51.

11. Amato R, Caton J, Polson A, Espeland M. Interporxinot gingival inflammation related to the conversion of a bleeding to a non bleeding state. $\mathbf{J}$ Periodontol. 1986;57:63-8.

12. Greenstein G. Contemporary interpretation of probing depth assessments: Diagnostic and therapeutic indications. J Periodontol. 1996;68:1194-205.

13. American Academy of Periodontology.Glossary of periodontal terms. Chicago: American Academy of Periodontology; 2001.

14. Apse P, Ellen RP, Overall CM, Zarb GA. Microbiota and crevicular fluid collagenase activity 
in the Osseointigrated dental implant sulcus: a comparison of sites in edentulous and partially edentulous patients. J Periodontal Res. 1989;24:96105.

15. Lang NP, Berglundh T. Woring Group 4 of seventh Euroup Workshop on Periodontology. Peri-implant diseases: Where are we now? Consensus of the seventh European workshop on periodontology.J ClinPeriodontol. 2011;38(suppl 11):178-81.

16. Schierano G, Pejrone G, Brusco P, Preti G. TNFalpha TGF-beta 2 and IL-1 beta levels in gingival and peri-implant crevicular fluid before and after de novo plaque accumulation. J ClinPeriodontal. 2008;35:532-8.

17. Tözüm TF, Turkyilmaz I, YamaliKN, Tümer C, Kilinc A, Kilinç K, et al. The effect of delayed versus early loading on nitric Oxide metabolism around dental implants: an 18-months comparative followup study. Int $\mathrm{J}$ Oral Maxilloface Implants. 2007;22:53-62.

18. Bondin S, Flemmig TF, Verraoli S. Role of fibroblast population in peri-implantitis, Int J Oral Maxillofac Implants. 2009;24:197-204.

19. Sasaki H, Hou L, Belani A, Wang CY, Uchiyama T, Müller R, et al. IL-10, but not IL-4, suppresses infection-stimulated bone resorption in vivo. $\mathrm{J}$ Immunol. 2000;165: 3626-30.

20. Defrance T, Vanbervleit B, Briere F, Durand I, Rousset F, Banchereau J. Interleukin 10 and transforming growth factor beta cooperate to induce anti-CD 40-activated naïve human b cells to secrete immunoglobulin A. J Exp Med. 1992;175:671-82.

21. Hijeer AH, Lazarus M, Turner D. Mageed RA, VencovsKyJ, Sinnott P, etal. IL 10 gene promoter polymorphisms in rheumatoid arthritis, Scand J Rheumatol. 1998;27:142-5.

22. Jinquiqn $T$, Larsen CG, Gesser B, Matsushima K, Thestrup-Pedersen K. Human IL-10 is a chemo attractant for CD8+T Lymphocytes and an inhibitor of IL-8 induced CD4+T lymphocyte migration. J Immunol. 1992;151:4545-51.

23. Owens JM, Gullagher AC, Chambers TJ. IL-10 modulates formation of osteclasts in murine hemopoietic cultures. J Immunol. 1996;157:93640.

24. MosmannT. Measurement of mouse and human interleukin-10. CurrProtocImmunol. 2001; Chapter 6:Unit 6.14.
25. Kirkpatrick LA, Feeney BC. A simple guide to IBM SPSS statistics for version 20.0. Student ed. Belmont, Calif:: Wadsworth, Cengage Learning; 2013.

26. Pietruski JK, Pietruski S, Stokowska W, Pattarelli GM. Serum levels of IL 1, IL 6 and IL8 in patients treated with dental implants. RoczAkad Med Bialynst. 2001;46:28-37.

27. Paul N.E, Shazikc, Harwardt M, Klee D, Salber J. Topographical control of human macrophages by a regularly micro-structured poly ringlidene fluoride surface. Biomaterials. 2008;29:4056-64.

28. Broggini N, McManus M, Hermann S. Peri-implant inflammation defined by the implant abutment interface. J Dental Res. 2006;85:473-8.

29. Liskmann S, Vihalemm T, Salum O, Zilmer K, Fischer K, Zilmer M. Correlations between clinical parameters and interleukin-6 and interleukin-10 levels in saliva from totally edentulous patients with peri-implant disease. Int $\mathrm{J}$ Oral Maxillofac Implants. 2006;21:543-50.

30. Sasaki H, Okamatsu Y, Kuwai T, Kent R, Taubman M, Stashenko P. The IL 10 knockout mouse is highly susceptible to Prophymonousgingivalis induced alveolar bone loss. J Periodontal Res. 2004;39:432-41.

31. Schierano G, Bellone G, Cassarino E, Pagano M, Preti G, Emanuelli G. Transforming growth factor beta and interleukin 10 in Oral implant sites. J Dent Res. 2003;82:428-32.

32. Guliz N, Abdullah C, Sevim G, Ezel B. Effect of inflammation on cytokine levels and bone remodeling markers in the peri implant fluid: a preliminary report. Int $\mathrm{J}$ oral Maxillofac Implants. 2012;59:313-6.

33. Casado PL, De Almeida A, Barboza EP, Duarte ME. Interleukin 1 beta and Interleukin 10 expressions in the peri implant crevicular fluid from patients with untreated peri implant disease. J Implant Dent. 2013;22:143-50.

34. Nogueira-Filho G, Pesun I, Isaak-Ploegman C, Wijegunasinghe $\mathrm{M}$, Wierzbicki T, McCulloch CA. Longitudinal comparison of cytokines in Peri implant fluid and gingival crevicular fluid in healthy mouths. J Periodontol. 2014;85:1582-8. 